\title{
Treatment of duodenal ulceration: reflections, recollections, and reminiscences
}

\author{
K D BARDHAN
}

(This article is one of a series linked with the Festschrift for Christopher Booth. See Gut Festschrift 1989; 30.)

This idiosyncratic contribution is a highly personal view of some of the developments that have taken place in the ficld of duodenal ulcer disease, particularly its management, which have been of interest to me.

Work done in Rotherham has been cited not because it is of particular merit but because such reference is unavoidable in a personal view; and for the same reason there is disproportionate discussion of cimetidine, for that is the drug with the longest scientific history and the compound with which I am most familiar.

My interest in ulcer disease started as a medical student in the Christian Medical College at Vellore, South India, where the condition was rife. At a chance meeting with Dr Booth, (as he then was) who was visiting Vellore, he mentioned in passing that if $I$ wanted to pursue the subject I should learn the importance of the scientific method and not practice medicine solely as an art. When I became his houseman a few years later he reinforced this lesson but it was not until I got to Rotherham that I got a chance to renew my interest in duodenal ulcer disease. At that time this disorder attracted little attention from physicians. Unfortunately, I started work on the pathophysiology of the disease, rather than on the therapy, on the grounds that there were unlikely to be any new major advances in treatment! My involvement with cimetidine, therefore, arose purely by accident.

\section{Cimetidine: the dawn of a new therapeutic era}

It had long been known that duodenal ulcer was invariably associated with the presence of gastric acid and that many patients (variably estimated from onetenth to over half) secreted an excess of acid. The reduction of acid secretion was therefore a logical approach to ulcer therapy. This was feasible surgically, a method which produced very good results, but there was no drug therapy that could lower acid secretion effectively and therefore the hypothesis could not be properly tested. Anticholinergies, which hitherto had been tried extensively, reduced acid secretion only modestly and their use was limited by side effects.

It was in this climate that the brilliant work of Dr James Black (now Prof Sir James Black) and his colleagues was to revolutionise ulcer treatment.' This key paper did not receive wide publicity in clinical circles, I seem to recall. Perhaps in part this was because there had been false dawns before but here was an advance in a different direction and of a different order of magnitude.

Burimamide, the first $\mathrm{H}_{2} \mathrm{RA}$ used in man, gave way to the much more powerful metiamide, which could be taken orally. This proved very effective in ulcer pain control and was the first drug that was conclusively proven to accelerate duodenal ulcer healing (Multicentre Trial, 1975․) Shortly before launch, however, metiamide had to be withdrawn because it produced (reversible) neutropenia. The backup drug, cimetidine, was then investigated and proved a powerful antisecretory agent and without the neutropenic side effects of its predecessor. The elegant dose ranging studies (reviewed by Pounder, 1984)' showed that a schedule of $200 \mathrm{mg}$ thrice daily plus $400 \mathrm{mg}$ at bedtime halved the 24 hour intragastric acidity. This was an order of reduction that hitherto could only be achieved by vagotomy. Therefore, there was reason to hope that cimetidine, by reducing acid secretion, might prove effective in ulcer healing. As there was no information then available relating to the degree of acid inhibition to ulcer healing rates, however, it could not be assumed that the above dose would necessarily prove optimal. Therefore, several ulcer healing studies were undertaken using a variety of dose schedules. These studies were led by the late Dr W B Burland and his colleagues of Smith, Kline, and French, and this is the stage where many of us came into this field.

It was a new experience for many of us to endoscope duodenal ulcer patients after one or two months' therapy and many, I suspect, will not forget the thrill 
of seeing ulcers disappear within weeks and of patients becoming free of pain within days. The results from many of these studies were presented at the second symposium on $\mathrm{H}_{2} \mathrm{RA}^{+}$at the Royal College of Physicians in London on 26 and 27 October, 1976. Most of us who attended felt that without doubt cimetidine did not merely add to ulcer therapy but transformed it dramatically. After all, after a month's treatment on placebo, the healing rate on average was $30 \%-35 \%$, whereas on cimetidine it was at least $75 \%$. The fact that most trials were small (by today's standards) did not appear to matter, for cimetidine was compared against placebo and the advantage of active treatment was so great that big studies seemed superfluous. It was a time when ulcer trials were simple to do: unlike today, patients would not already have been pretreated with an $\mathrm{H}_{2} \mathrm{RA}$ for cimetidine was the first such drug widely used; there were not endless exclusion clauses; single centre studies could be done; and finally, the trial record books were thin, compared with the large tomes of today!

The story of the exciting discoveries and developments leading to the clinical use of cimetidine is recounted very well by $\mathrm{W} A \mathrm{M}$ Duncan and $\mathrm{M} E$ Parsons, key members of the team that made these remarkable advances. Cimetidine was duly launched on 15 November 1976 and it seemed that duodenal ulcer would no longer pose a problem.

Subsequently, other $\mathrm{H}_{2} \mathrm{RAs}$ followed: ranitidine (1981), famotidine (1987) and nizatidine (1987), and roxatidine and sufotidine may follow soon. All these $\mathrm{H}_{2}$ RAs produce similar healing rates: at one month on placebo healing is approximately $35 \%-4(0 \%$ whereas on $\mathrm{H}_{2}$ RAs it is $75 \%-85 \%$; and at three months, it is about $95 \%$. In some smaller trials, higher (and lower) rates have been observed but the above figures generally apply. Meta-analysis of various comparative trials shows that ranitidine produces a slightly greater healing rate than cimetidine. This is not apparent when examining individual studies. When the trials are pooled, however, the difference is statistically significant, although in clinical terms is still small. Thus, pooling the results of 44 studies (4374 patients), healing at four weeks was: on cimetidine $70.4 \%$, and on ranitidine $77.7 \%$." In recent years, healing rates at two weeks have also been examined. In general, it is just under $50 \%$ on cimetidine and just over it on ranitidine. Finally it should be emphasised that, despite the success, there have been many failures with $\mathrm{H}_{2} \mathrm{RAs}$ as well and the following have been withdrawn from further trial work, mainly because of side effects or toxicity and related problems during animal or human studies: metiamide (Smith, Kline, and French), tiotidine (Imperial Chemical Industries), SKF 93479, SKF
93574, oxmetidine (Smith, Kline, and French), loxtidine (Glaxo), zaltidine (Pfizer), ICI 162846 and WY 45727 (Wyeth).

\section{7 onwards: uncertainties, doubts and questions}

Amidst the early triumph, there were uncertainties. First, there was little information available on longterm therapy. Trials on maintenance treatment had been started but there was no guidance as to which patient should be treated with this regime; and almost by default many patients were put on such treatment for no very good reason. In the absence of hard facts, not surprisingly, various views (often divergent) abounded, the only common factor being the certainty with which they were put forward. These included: short term treatment only; one or two relapses and then surgery; maintenance treatment for all. Which approach should one follow? On what basis could one judge the relative merits of the different strategies?

Second, several of the patients in Rotherham who participated in the original studies needed retreatment. By default, rather than by design, I roughly used the same protocol as in the clinical trial and, therefore, saw the patients more frequently than was really necessary. I was surprised by comments some of them made that the 'magic tablets' seemed less effective the second time around. Also, in some, the healing rate was not quite as quick. Was it possible that cimetidine became less effective with repeated use or were the patients simply expecting too much?

Third, it was clear from the early studies and the subsequent ones done in the UK and elsewhere that amongst placebo treated patients, ulcers in about one-third healed quickly (by one month) and pain relief was swift. I was therefore wrong in my assumption that without active treatment, ulcers simply would not heal quickly and that patients would remain symptomatic. In addition to forcibly showing the value of the placebo controlled trial, it raised the question: is ulcer disease really always severe?

Fourth, the major USA multicentre trial gave a very different picture: cimetidine proved to be only marginally better than placebo, as the healing rate on cimetidine was low, whilst that on placebo relatively high. Analysis of results of trials from different parts of the world showed that the therapeutic gain (the difference in healing rates on placebo and on cimetidine) varied considerably, being lowest in Lausanne (placebo healing rate of almost $7(0 \%)$ ) and highest in London (placebo healing of only $20 \%$ ). 'Thus, results from one country could not necessarily be extrapolated to another, and the effect of confounding variables such as population differences and antacid 
consumption (hitherto considered unimportant) could not be ignored.

\section{Altering the natural history of the disease}

Relapse is a cardinal feature of duodenal ulcer disease: over 12 months, $50 \%$ to $90 \%$ of patients have an ulcer recurrence, most with symptoms. In the early days of cimetidine treatment there were worries that acid inhibition would lead to hypergastrinaemia which, when treatment was stopped, would result in acid rebound, thus increasing the relapse rate, perhaps with ulcer complications. The reports of early relapse, sometimes severe, on withdrawal of therapy supported this view. It was thought that maintenance treatment might prevent this with tapering of drug dosage until acid homeostatic mechanisms returned to normal. Another view was that by prolonging treatment beyond ulcer healing, the residual duodenitis could be cleared, leading to a more 'durable' healing.

Several studies then investigated whether maintenance treatment for six to 12 months would be followed by a decreased tendency to relapse. Overall these studies showed that the tendency to relapse was not related to the length of preceding maintenance treatment. Once treatment was stopped, there was a high recurrence rate, $53 \%$ (in three months) - 77\% (at six months), very similar to that in patients who did not receive any maintenance therapy after ulcer healing."

In a large study we tried the effects of medium term treatment with full dose therapy with cimetidine $1 \mathrm{~g}$ daily. One hundred and ninety four (of 248) patients whose ulcer(s) had healed by one month on cimetidine $1 \mathrm{~g}$ daily were randomly allocated to further treatment with the same dose of cimetidine for two months $(n=63)$, or five months $(n=66)$ or placebo $(n=65)$; thereafter, all patients received placebo for up to two years. The cumulative symptomatic relapse rates in the groups who in total received cimetidine for one month, three months and six months were $77 \%, 80 \%$ and $90 \%$, respectively; and the symptomatic plus silent relapse rates - that is, total relapse rates - were $100 \%, 92 \%$ and $92 \%$, respectively."'

Clearly (with rare exceptions: see below), low dose or full dose maintenance treatment protected against relapse only for as long as treatment lasted. Once treatment was stopped, the patient 'starts where he left off'." The editorial writer in the British Medical Journal of 3 June, 1978 was therefore very far seeing when he entitled his article 'Cimetidine for ever (and ever and ever...)?" The recent international study on maintenance treatment, however, gave an importantly different result. In this very large study (1842 patients recruited), of the patients who remained in remission for two years on cimetidine $400 \mathrm{mg}$ nightly, one in five was transferred to placebo treatment. Over the next 12 months, $6 \%$ of the 393 patients who continued on cimetidine had a symptomatic relapse compared with $22 \%$ of the 90 patients on placebo (symptomatic plus silent relapse rates: $9 \%$ and $29 \%$, respectively). The relapse rate on placebo was far lower than that usually seen, suggesting that a longer course of maintenance treatment may alter the natural history of the disease. ${ }^{12}$

A different approach has been to examine the relapse rates after healing with various agents. It has been known since 1980 that relapse after $\mathrm{H}_{2} \mathrm{RA}$ healing is not uncommonly higher than after healing with drugs of a different therapeutic class, such as carbenoxolone, colloidal bismuth subcitrate, proglumide, trithiozone, antacid-anticholinergic combination and acetozolamide. ${ }^{1:}$ The individual studies of themselves were not sufficiently large to draw firm conclusions. By meta-analysis of the different studies, however, it was possible to form a clearer picture. Four such meta-analyses ${ }^{1+}$ have clearly shown that relapse after colloidal bismuth subcitrate (CBS) is generally consistently and significantly less than after $\mathrm{H}_{2} \mathrm{RA}$ treatment. Relapse after healing on misoprostol and sucralfate is also less than after $\mathrm{H}_{2} \mathrm{RA}$ treatment but the differences are not quite as striking. The conclusion is that if short term $\mathrm{H}_{2} \mathrm{RA}$ treatment does not alter the natural history and that the subsequent relapse rate is the true pattern, then treatment with colloidal bismuth subcitrate changes the natural history for the better; this is the most widely held view (the opposite view is that if relapse after colloidal bismuth subcitrate is the norm, then treatment with $\mathrm{H}_{2} \mathrm{RAs}$ increases the tendency to relapse).

Thus, the natural history of the disease can be altered by medical treatment but by means unforeseen in the early 1980s, namely, by the choice of healing agent and that too by short term therapy. It is ironical, though, that CBS, which has been available for many years and until recently was poorly investigated, should turn out to be the drug to so change the natural history.

\section{Longterm medical management: maintenance treatment}

Maintenance treatment has now been widely used to reduce duodenal ulcer relapse. The dose of $\mathrm{H}_{2} \mathrm{RA}$ used is half the healing dose taken at bedtime. Successful though such treatment is, I remain puzzled how this dose regime came to be developed!

From 1976 onwards, when many maintenance treatment trials with cimetidine were started and studies with other $\mathrm{H}_{2} \mathrm{RAs}$ followed, the principal 
questions to be answered were: Was such treatment effective? Would it remain effective in the long term? That is, would relapse be prevented or only postponed. For which patient? For how long? At which dose'? Should silent ulcer be looked for? Was prolonged therapy safe?

Most studies were relatively short, usually up to a year and a few up to two years. The majority showed a clear benefit of treatment: compared with a relapse rate at one year of $50 \%-80 \%$ on placebo, on cimetidine $400 \mathrm{mg}$ nightly, it was on average about $20 \%$, approximately one-third of the recurrences being silent. Similar patterns were observed with the other $\mathrm{H}_{2}$ RAs. ${ }^{15}$

It is only in the last two years that the results of three maintenance treatment trials with cimetidine over much longer periods have become available. The results are similar and they clearly show the efficacy and safety of such therapy. Taking the Anglo-Irish four centre collaborative study ${ }^{\text {th }}$ as an example, 321 patients were treated for up to six years with cimetidine $400 \mathrm{mg}$ nightly. The principal findings are as follows: first, most relapses occurred in the first year, the cumulative symptomatic recurrence rate being: year $1,13 \%$; year $2,19 \%$; year $3,24 \%$; year 4 , $26 \%$; and year $5,28 \%$. Thus, treatment remained effective and genuinely reduced relapse rates.

Second, a higher proportion had a silent relapse, which at years 1-5 were, respectively, 20\%, 26\%, $31 \%, 33 \%$ and $35 \%$.

Third, on relapse, a further course of low dose maintenance treatment (after rehealing) gave at least as good results as the first course. Of 95 patients retreated, in 56 the second remission was longer than the first, in 24 it was shorter (and the remainder continued in remission until the cut off point).

Fourth, complications were rare: only six patients suffered such problems.

Finally, treatment was safe: on average there was one event per patient every 1.4 years of continuous treatment; and in only two patients were the adverse events directly as a result of the drug.

Thus, prolonged maintenance treatment with cimetidine $400 \mathrm{mg}$ nightly is generally successful and safe. It seems to me that maintenance therapy is only moderately effective when judged by its ability to suppress the disease process entirely for silent relapse on treatment is high; but it is a very effective way of keeping most patients virtually asymptomatic. Similar, perhaps marginally better, results were achieved with longterm ranitidine treatment. ${ }^{7}$

One area which, surprisingly, has not been much explored is in using a higher dose of $\mathrm{H}_{2} \mathrm{RA}$ for maintenance therapy. In one study, the relapse rate on cimetidine $400 \mathrm{mg}$ nightly was $36 \%$; of those who relapsed and after rehealing were put on maintenance treatment with cimetidine $400 \mathrm{mg}$ twice daily, the relapse rate was reduced to $17 \%$." Apart from this encouraging result, there is virtually no other information available.

We are now getting some of the answers to the questions on maintenance treatment posed over 10 years ago. Longterm efficacy and safety are proven. There probably is no need to search for silent ulcer disease with periodic check endoscopies in the asymptomatic because as long as the treatment is continued, there is a strong tendency to heal." There is, however, no information on how long treatment should be given for. Unless it can be proven that a long but defined period of treatment alters the natural tendency of the disease to relapse when therapy is stopped, it seems to me inevitable that treatment will have to be given permanently for the tendency to relapse probably lasts life long." Therefore, the suggestion frequently made that maintenance treatment should be given only for a few years and then stopped 'to see what happens', whilst understandable, does not seem entirely sound. There is no agreement on the indications for life long treatment.

In this centre, patients who have severe disease (troublesome symptoms and/or frequent relapses) or who are at greater risk of dying should complications occur (regardless of severity), are chosen for permanent maintenance treatment. The specific (but arbitrary) criteria used for selection are: (1) Age $\geqslant 60$ years; (2) Other severe illnesses present, regardless of age - for example, major cardiopulmonary disease; (3) Previous hacmorrhage or perforation, particularly if there have been repeated episodes or if the complication has recurred recently; (4) Need to take non-steroidal anti-inflammatory drugs regularly, regardless of age; (5) Severe disabling pain which develops abruptly, even if relapses are infrequent ( $\leqslant$ two per year); (6) Frequent relapses - that is, $\geqslant$ three per year: (7) Failure of a trial of intermittent treatment - that is, relapses occur more frequently or are more disabling or complications occur; (8) Refractoriness, either at onset or later on. (Surgery is the alternative for otherwise fit patients who meet any of the criteria 3, 5, 6, 7 and 8 ).

\section{Longterm medical management: intermittent treatment}

Intermittent treatment came to be used in Rotherham not as a result of scientific planning but because of a poverty! In 1977, cimetidine was considered an expensive drug; the hospital pharmacy's reluctance to give me large supplies was matched by the general practitioners' disinclination to prescribe maintenance therapy, despite the fact that at the time 
it was thought to be the best method of longterm treatment. Thus, I had to eke out my research stock by rationing!

The patients were treated only for one month (in the majority) or two months and healing confirmed by endoscopy. A further course was given if and when there was a recurrence of significant symptoms and of reulceration proven by endoscopy. The results, to my surprise, were better than expected. After a single course of treatment $36 \%$ (of 125 patients) did not need further treatment over the next 12 months; $37 \%$ had one further course and $20 \%$ had two courses; only $7 \%$ needed three or more courses. Thus, most patients could be managed on short courses of healing treatment, repeated as needed." Other investigators obtained roughly similar results, the majority of patients needing up to two treatment courses per year. Complications were rare.

Thus, contrary to the commonly held view, the majority of patients stay in remission for fairly long periods (though they have mild symptoms easily controlled by the occasional dose of antacid); only a minority have aggressive disease characterised by frequent relapses. It is the latter which is seen in hospitals and being unrepresentative gives the misleading impression that most patients have severe and frequent pain.

Intermittent treatment is ideally suited for longterm treatment in the younger, otherwise fit patient with mild disease and is now widely used. In this centre, patients are selected for this form of therapy provided they meet all the following criteria at each relapse which, it must be emphasised, are arbitrarily chosen: (1) Age <60 years; (2) No other serious illness; (3) No previous haemorrhage or perforation and no current pyloroduodenal stenosis; (4) Not on regular treatment with non-steroidal anti-inflammatory drugs; (5) Ulcer symptoms develop gradually (giving enough time to restart treatment); (6) Not more than two relapses per year; (7) Ulcer is nonrefractory.

With time, the disease becomes aggressive in some patients; others age or develop other illnesses: they are transferred to maintenance treatment but their numbers are replenished by new patients referred from the community. Therefore at any one time, about two-thirds of patients seen in this unit are managed by intermittent treatment and the remainder by maintenance treatment (or sometimes by surgery).

\section{Intermittent treatment: improving the results}

Two different approaches may give better results than those currently obtained with $\mathrm{H}_{2} \mathrm{RA}$ treatment. First, the healing treatment could be made shorter by using omeprazole. Second, the length of remission could be increased by using colloidal bismuth subcitrate instead of $\mathrm{H}_{2}$ RAs (sec earlier section).

A. OMEPRAZOLE

This remarkable drug causes profound prolonged inhibition of acid secretion, a dose of $20 \mathrm{mg}$ daily resulting in $\geqslant 90 \%$ reduction in the 24 hour acidity; and a $40 \mathrm{mg}$ daily dose causes virtual achlorhydria. Presumably it is the magnitude of the antisecretory effect which is responsible for the higher healing rates achieved with omeprazole. In comparative clinical trials, healing at two weeks is always greater on omeprazole than on $\mathrm{H}_{2} \mathrm{RA}$. The results, pooled from nine studies, are respectively $69 \%, 50 \%$ (mean values); and our own results give values, respectively, of $83 \% v 53 \%$."

In several studies two weeks of treatment produces healing similar to that achieved with a standard four week course of $\mathrm{H}_{2} \mathrm{RA}$ therapy. Thus, repeated courses of omeprazole may become an important form of intermittent treatment in the future; and because the courses are likely to be shorter than with $\mathrm{H}_{2}$ RA treatment (two weeks instead of four weeks), patient treatment compliance may well improve.

B. COLLOIDAL BISMUTH SUBCITRATE (CBS)

Using a meta-analysis of six comparative studies in which relapse rates after $\mathrm{CBS}$ and $\mathrm{H}_{2}$ RA treatment were compared, it was calculated that at one year after treatment $85 \%$ of patients would have relapsed after successful $\mathrm{H}_{2} \mathrm{RA}$ treatment compared with only $59 \%$ after CBS therapy, which in turn resulted in a monthly relapse rate of $17 \%, 7 \%$ respectively. Thus, the need for retreatment is much less frequent after $\mathrm{CBS}$ than after $\mathrm{H}_{2}$ RA healing making it attractive to use for intermittent treatment.

Our own results are at slight variance. Colloidal bismuth subcitrate and ranitidine gave virtually identical rates for healing and for pain relief on repeated use. After the first healing course, the cumulative relapse rates at six, 12 , and 18 months were as follows: after ranitidine, $37 \%, 74 \%$ and $81 \%$ respectively; and after CBS, $40 \%, 62 \%$ and $69 \%$ respectively - that is, no significant difference. After the second healing course, however, there was significantly less relapse after CBS treatment, particularly in the early months, thus the relapse rates at six, 12 and 18 months being, after ranitidine: $72 \%, 93 \%$ and $96 \%$; and after CBS, $27 \%, 74 \%$ and $83 \%$ respectively. I am unable to explain why in this centre the protective effect of CBS was apparent only after a second treatment course. ${ }^{-+}$

Taking all these findings together, CBS may prove superior to $\mathrm{H}_{2} \mathrm{RA}$ for intermittent treatment. In my view, however, the benefit of CBS needs to be proven 
by prospective experiments in which patients receive repeated courses of therapy, as would happen in routine clinical practice. This would be better than drawing conclusions based on the outcome of a single course of healing treatment.

The mechanism whereby CBS exerts its protective effect is unknown. It is widely assumed that it is because of its ability to eradicate Campylobacter pylori; certainly the relapse rates in patients where the organism has been cleared are much less than in patients where it persists, as happens after $\mathrm{H}_{2} \mathrm{RA}$ treatment. Other mechanisms may be important, however, for example, its ability to stimulate prostaglandin production. Whatever mechanisms are responsible, the prolonged protective effect of CBS may be (closely) connected with the fact that the drug accumulates in the body: large amounts are excreted in the urine for at least three months after stopping treatment. Therefore, unlike $\mathrm{H}_{2} \mathrm{RAs}$, CBS has a depot effect.

In the future, intermittent treatment with omeprazole and with CBS is likely to become important, though for a long time yet, this form of treatment is likely to remain dominated by the $\mathrm{H}_{2} \mathrm{RA}$.

\section{Refractory duodenal ulcer}

Even in the early clinical trials of ulcer healing it was clear that in a minority of patients, healing of duodenal ulcer took longer than a month; it seemed natural there should be 'rapid healers' and 'slow healers'. In this centre, however, where patients were repeatedly treated and the process monitored by endoscopy, it was observed that some patients who previously had responded swiftly to cimetidine no longer did so. Such patients with refractory ulcer (defined as non-healing on cimetidine $1 \mathrm{~g}$ daily given for at least three months) were more commonly seen than I had previously assumed. Thus of 3235 patients over 13 years, $691(21 \%)$ had $\geqslant$ one refractory episode; $181(6 \%)$ had $\geqslant$ two such episodes; $40(1 \%)$ had $\geqslant$ three episodes; and $10(0.3 \%)$ had $\geqslant$ four episodes; and two patients had five episodes of refractoriness (unpublished observations). In up to half the patients, doubling or trebling the dose of cimetidine resulted in healing but there remains a hard core of patients in whom the disease persists that is, patients with ultra-refractory duodenal ulcer (defined as non-healing on cimetidine $2 \mathrm{~g}$ or $3.2 \mathrm{~g}$ daily given for at least three months).

Refractory duodenal ulcer has been the focus of a great deal of research interest in recent years; many centres have concentrated on pathophysiologic abnormalities, particularly of acid secretion and its suppression on treatment. In this centre, however, acid secretion and the degree of inhibition on cime- tidine was similar in patients with refractory and with non-refractory disease." Abnormalities in mucosal defence and the role of emotional stress have been little studied. Hansen and Knigge ${ }^{2 h}$ observed that $58 \%$ of their patients who did badly after surgery had such problems compared with only $27 \%$ who did not; and in this centre, a striking feature has been that many of the patients who remain symptomatic despite high dose $\mathrm{H}_{2} \mathrm{RA}$ treatment are at the time under great emotional strain.

Most studies on the pathophysiology of refractory ulcer have been cross-sectional - that is, certain characteristics have been compared in refractory and in non-refractory patients at a particular time. Various differences have been found by some investigators but have been denied by others. In my view, however, none of these differences necessarily explain why patients become refractory: why did they once respond well to $\mathrm{H}_{2}$ RA but do so only inadequately (or not at all) now? For example, of 691 refractory ulcer patients whose healing was monitored in this centre (and excluding $\mathrm{H}_{2} \mathrm{RA}$ treatment from their family doctors before referral), $323(47 \%)$ were refractory on their first course of cimetidine; arguably they could be called slow or non-healers. One hundred and fifty seven patients $(23 \%)$ became refractory only on the second healing course; 112 $(16 \%)$ on the third course; $46(7 \%)$ on the fourth course; $26(4 \%)$ on the fifth course; $19(3 \%)$ on the sixth course; four $(0 \cdot 6 \%)$ on the seventh course; and finally, two $(0 \cdot 3 \%)$ on the eighth course (unpublished observations). Finding the answer may well need longitudinal studies. As it is difficult to predict which patient will become refractory, it is not easy to make comparisons in the prerefractory and refractory state, particularly when invasive investigations are involved - for example, acid secretion.

My own hunch is that in refractoriness there is a degree of relative 'mucosal exhaustion', such that the mucosa can no longer repair itself at its usual rate when acid secretion is partially suppressed with standard dose $\mathrm{H}_{2} \mathrm{RA}$ treatment. The lesions are not static; serial endoscopy shows that as lesions heal, new ones appear, indicating that the mucosa does try to achieve repair. In active duodenal ulcer the proliferation of duodenal cells at the ulcer edge is greatly increased to fill the breach. It may well be that in refractory disease the heightened proliferation is simply not great enough to catch up with the continuing damage - that is, a state of 'high-output failure' (to make a cardiological analogy). ${ }^{27}$ For healing to take place, either greater acid inhibition or stimulation of mucosal defence is needed. I think refractoriness may be part of the natural history of the disease and affects only a small proportion of patients. In the pre- $\mathrm{H}_{2} \mathrm{RA}$ years such patients would have been 
operated upon early and would be indistinguishable from the many more who underwent surgery because conservative medical treatment had failed. As medical treatment is now far more successful and elective surgery needed less often, however, such patients do stand out.

The medical management of refractory duodenal ulcer remains somewhat confusing and the alternative approach, of surgery, often gives results which are less good than with non-refractory disease. The options for short term medical treatment are: continued treatment with the same $\mathrm{H}_{2} \mathrm{RA}$ at the same dose or at a higher dose; changing to a more powerful $\mathrm{H}_{2} \mathrm{RA}$; adding an antimuscarinic to the $\mathrm{H}_{2} \mathrm{RA}$ (to achieve greater acid inhibition); using omeprazole to give a more effective reduction of acid secretion; or by using a mucosal defence agent such as colloidal bismuth subcitrate or sucralfate. Of these, treatment with omeprazole or with colloidal bismuth subcitrate has given good results, although more studies are needed to confirm these findings. The main observations are summarised in the Table.

Longterm medical management remains problematical for there is no proven method which effectively keeps refractory duodenal ulcer patients in prolonged remission once healing has been achieved. In this centre, the relapse rate on standard low dose maintenance treatment with cimetidine $400 \mathrm{mg}$ nightly has given a much higher rèlapse rate compared with patients with non-refractory disease. The cumulative symptomatic rate at one year and at two years was, respectively: non-refractory ulcer patients $13 \%$ and $20 \%$; and in refractory ulcer patients $45 \%$ and $48 \%$; the total relapse rates - that is, symptomatic plus silent, were respectively, $28 \%$ and $43 \%$ at one and two years in non-refractory disease compared with $83 \%$ and $96 \%$ in refractory ulcer patients.--

The alternative approach is to use a higher dose of $\mathrm{H}_{2} \mathrm{RA}$ for maintenance treatment when the standard low dose has failed. There are few studies on this point and the results are conflicting. Our own findings (open studies; unpublished) suggest maintenance treatment with cimetidine $1 \mathrm{~g}$ daily may be effective when the $400 \mathrm{mg}$ nightly dose has failed. Maintenance treatment with omeprazole $40 \mathrm{mg}$ may prove very effective: no patient (of 83 treated) relapsed by one year." As this dose produces virtual achlorhydria its use will, I think, be limited to the few patients with very severe disease, in the first instance, and will not be routinely used for the longterm management of refractory disease. The $20 \mathrm{mg}$ dose for maintenance is more attractive but as yet this indication is not authorised.

Surgery, the traditional and ultimate backstop when medical treatment fails has, in refractory ulcer disease, not been quite so unequivocally successful as in non-refractory disease, either because ulcer recurrence rates are higher and/or non-ulcer pain is more frequent. Certainly, some surgeons have obtained good results."

Thus, there is a group of patients who are likely to fail both on medical and on surgical treatment. I do not think this is a new problem. In the pre- $\mathrm{H}_{2} \mathrm{RA}$ years, when medical treatment often failed and many more patients were electively operated upon, the small group with disease that today we would call $\mathrm{H}_{2} \mathrm{RA}$-refractory, could not have been recognised as such; but I suspect they accounted for a high proportion of the patients who had poor results. Now that treatment is available which is effective for most, such patients stand out.

The management of refractory duodenal uleer remains unsatisfactory. Controlled trials are needed, particularly to determine effective longterm management but such studies are difficult. Despite the fact that controlled trials have not unequivocally proven the efficacy of cimetidine, in this centre we use high doses of this drug for healing and reserve omeprazole for the few in whom the disease remains active and symptomatic; and for longterm therapy cimetidine $1 \mathrm{~g}$ daily remains our drug of choice for the majority of patients continue in remission and time has proven such treatment safe.

\section{Impact of modern medical treatment on duodenal ulcer surgery}

It is commonly assumed that the substantial decrease in elective antiulcer surgery is a result of effective $\mathrm{H}_{2} \mathrm{RA}$ therapy, ignoring evidence that operation rates have been falling for 2()-30 years. Nevertheless, studies both in the UK and USA suggest that $\mathrm{H}_{2} \mathrm{RA}$ have had a considerable effect. In contrast there has been little change in the rate of surgical intervention for acute complications of duodenal ulcer."

I have recently looked at the use of $\mathrm{H}_{2} \mathrm{RA}$ and its effect on surgical practice in Rotherham (population: 250000) and in the Trent Regional Health Authority (RHA) (population: 4.6 million) (of which Rotherham is a part), and compared the mean admission and operation rates in the pre- $\mathrm{H}_{2} \mathrm{RA}$ period (1972-1976) with those in the subsequent years (1977-1984).

In the Trent RHA, the use of $\mathrm{H}_{2} \mathrm{RA}$ has risen $3 \cdot 7$ fold from 1978 to 1983 (the last point at which such data are available) and presumably has risen still further. Yet the mean admission rates for perforation, haemorrhage and for severe pain but without complications showed no decline in the $\mathrm{H}_{2} \mathrm{RA}$ years; in fact in patients over the age of 65 years, admissions increased by $33 \%, 28 \%$, and $36 \%$ respectively. In contrast, elective surgery fell in this period by $43 \%$. 
Table Medical management of refractory duodenal ulcer: healing the ulcer

\begin{tabular}{|c|c|}
\hline Options & Outcome: Healing \\
\hline Continue $\mathrm{H}_{2} \mathrm{RA}$ : & Open studies \\
\hline Same dose & $\begin{array}{l}\text { Continued cimetidine (lg } \\
\text { daily) } 14 \%\end{array}$ \\
\hline Increased dose & $\begin{array}{l}\text { Cimetidine }(2 \text { g daily }) 61 \% \\
\text { Mean time to heal on } \\
\text { cimetidine } 7.4 \text { months ( } 4-14 \\
\text { months) }\end{array}$ \\
\hline $\begin{array}{l}\text { Change to more potent } \\
\mathrm{H}_{2} \mathrm{RA} \text { : }\end{array}$ & Probably greater healing \\
\hline cimetidine $\rightarrow$ ranitidine & $\begin{array}{l}\text { In one controlled study, at } 6 \\
\text { weeks, } 60 \%, 1.71 \% \\
\text { respectisely }\end{array}$ \\
\hline Add pirenzepine & $\begin{array}{l}2 \text { of } 3 \text { studies favour } \\
\text { combination } \\
\text { On cimetidine }(0 \%-40 \%: \text { on } \\
\text { combination } 80 \%\end{array}$ \\
\hline Change to sucralfate & $\begin{array}{l}\text { Single open study. Healing: } \\
\quad 61 \%\end{array}$ \\
\hline Change to colloidal & Most heal \\
\hline bismuth subcitrate & $\begin{array}{l}\text { Cimetidine } 40 \% \text {. CBS } \\
82 \%-8.5 \%\end{array}$ \\
\hline Change to omeprazole & $\begin{array}{l}\text { Most heal } \\
\text { Cimetidine } 39 \%-59 \% \\
\text { Omeprazole } 82 \%-89 \%\end{array}$ \\
\hline
\end{tabular}

The surprising finding, however, was that the change in the annual rate (as opposed to comparing mean rates in the pre- $\mathrm{H}_{2} \mathrm{RA}$ and $\mathrm{H}_{2} \mathrm{RA}$ periods) for elective operation showed that the decline was no greater than the spontaneous decrease that had been taking place in the preceding years. Thus, any additional effect resulting from using $\mathrm{H}_{2} \mathrm{RA}$ could not be discerned.

In Rotherham, $\mathrm{H}_{2} \mathrm{RA}$ use had increased rather more, 6-2-fold. Despite this intensive use, there was no reduction in emergency admissions. Elective surgery fell by $91 \%$, however, and unlike in the Trent RHA, the decrease in annual rate was significant."

The failure of $\mathrm{H}_{2} \mathrm{RA}$, even when used intensively, to reduce emergency admission is perhaps not entirely unexpected for several reasons. First, many patients, particularly the elderly, have no previous dyspeptic history or one that is mild and is therefore not investigated. Second, even in patients known to have ulcer disease, recurrence may not be preceded by warning symptoms and they may present with incapacitating pain, hacmorrhage or perforation. Finally, the increasing use of non-steroidal antiinflammatory drugs may make a higher proportion of the elderly more vulnerable to developing ulcer complications. In the first two groups, there is no opportunity to intervene early with medical treatment; and maintenance treatment, which would reduce such complications, can be given only to those already known to have duodenal ulcer.
It seemed hard to believe that powerful modern treatment apparently had no distinct and discernible effect on elective ulcer surgery in the Trent RHA, particularly after talking to many surgeons who confirmed that many patients with troublesome disease would surely have been operated upon had it not been for the availability of such drugs. In contrast, in Rotherham the intensive use (perhaps over use) of these drugs has led to a profound and significant fall in operation rates. The explanation for the different rates of fall in Trent RHA and in Rotherham is, perhaps, as follows. The natural history of the disease is changing, probably resulting in a lower proportion of young and middle age groups (the groups most likely to undergo elective operation) who develop severe disease. Individual patients who develop troublesome problems can now be managed medically but the consequent reduction in operation rates, unless great, cannot be separated from the (perhaps greater) effect of natural changes. When medical treatment is used more intensively, however, as in Rotherham, and patients who in most centres would be operated upon are instead managed by medical means, there is a definite additional discernible effect, over and above that produced by natural changes.

In this centre, we now electively operate (unless the patient chooses otherwise) when treatment with cimetidine $3.2 \mathrm{~g}$ daily (or with ranitidine $0.9 \mathrm{~g}$ daily) plus antacids, and if necessary inpatient bed rest, fails to heal the ulcer and to control symptoms. From 1972-1975 (before cimetidine), on average, 60 elective operations were done per year; in 1979-1984, the corresponding figure was nine; and in 1985, 1986 and 1987, only seven, two and two operations respectively were done. I suspect it is not only the widespread use of medical treatment in patients with duodenal uleer but also the use of high-dose $\mathrm{H}_{2} \mathrm{RA}$ therapy, where necessary, that is, targetted treatment, which has a bearing on determining whether the reduction in elective surgery will be any greater than that produced by natural decrease.

\section{Clinical research in a District General Hospital}

Rotherham DGH is no Hammersmith Hospital. When I was first appointed, I missed the physical facilities for clinical research and the necessary 'critical mass' of people interested in work of this nature; and the difficulties were compounded by my own numerous shortcomings. I recall, from almost 20 years ago, commenting to Professor Booth that clinical research was difficult to do outside teaching centres; his reply was that opportunities abounded everywhere, in centres large and small: it was a matter of seizing them. I was unconvineed then but 
with the passage of time and growing experience, I have come to realise that he was right: that clinical research can be pursued in small centres and that gastroenterology, which has grown so rapidly in the last two decades, has provided a great number of opportunities.

The spirit of enquiry which Professor Booth encouraged was in turn infectious and stimulating and I have benefitted from it. I hope Sir Christopher will look not entirely unkindly upon the continuing (if unsteady) efforts of his former houseman!

I am grateful to Miss Beverley Mason for typing the paper.

District General Hospital,

Rotherham S60 2UD

\section{References}

1 Blum AL. Is placebo the ideal anti-ulcer drug? In: Bianchi Porro G, Bardhan KD, eds. Peptic ulcer disease Verona: Cortina International, 1982: 57-61.

2 Binder HJ, Donaldson RM. Effect of cimetidine on intrinsic factor and pepsin secretion in man. Gastroenterology 1978; 74: 371-5.

3 McIsaac RL. McCanless I, Summers K, Wood JR. Ranitidine and cimetidine in the healing of duodenal ulcer: meta-analysis of comparative clinical trials. Aliment Pharmacol Ther 1987; 5: 369-82.

4 Duncan WAM. Parsons ME. Reminiscences of the development of cimetidine. Gastroenterology 1980; 78: 620-4.

5 Burland WL, Simkins MA, eds. Cimetidinc. Proceedings of the second international symposium of histamine $H_{2}$ receptor antagonists. Amsterdam, Oxford: Excerpta Medica, 1977.

6 Pounder RE. Histamine $\mathrm{H}_{2}$ receptor antagonists and gastric acid secretion. Pharmac Ther 1984; 26: 221-34.

7 A Multicentre Trial. Treatment of duodenal ulcer by metiamide. Lancet 1975; ii: 779-81.

8 Black JW, Duncan AM, Durant CJ, Grancllin CR, Parsons EM. Definition and antagonism of histamine $\mathrm{H}_{2}$-receptors. Nature 1972; 236: 385-90.

9 Bardhan KD. The short and medium-term treatment of duodenal ulcer with cimetidine. In: Bianchi Porro G, Bardhan KD, eds. Peptic ulcer disease Verona: Cortina International, 1980: 85-106.

I0) Bardhan KD. Cole DS. Hawkins BW. Does treatment with cimetidine extended beyond initial healing of duodenal uleer reduce the subsequent relapse rate? Br Med J 1982; 284: 621-3.

11 Anonymous. Cimetidine for ever (and ever and ever...)? [Editorial]. Br Med J 1978; i: 1435-6.

12 Walan A. Bianchi Porro G, Hentschel E, Bardhan KD. Delattre M. Maintenance treatment with cimetidine in peptic ulcer disease for up to 4 years. Scand J Gastroenterol 1987; 22: 397-406.

13 Bardhan KD. Long-term management of duodenal ulcer - a physician`s view. In: Baron JH, ed. Cimetidine in the 80 's. Edinburgh: Churchill Livingstone 1981: $95-112$.
14 Dobrilla G, Vallaperta P. Amplatz S. Influence of ulcer healing agents on ulcer relapse after discontinuation of acute treatment: a pooled estimate of controlled clinical trials. (iut 1988; 29: 181-7.

15 Misiewicz JJ, Bradbury JE. Review of trials of maintenance treatment for the prevention of duodenal ulcer recurrence. In: Misiewicz JJ, Wood JR, eds. Ranitidine therapeutic advances. Amsterdam: Elsevier 1984.

16 Bardhan KD. The Anglo-Irish Cimetidine Long-term Study Group. Six years of continuous cimetidine treatment in peptic ulcer disease: efficacy and safety. Aliment Pharmacol Ther 1988: 2: 395-405.

17 Penston JG, Wormsley KG. Long term treatment of duodenal ulcers [Abstract]. Gastroenterology 1988; 94: A.349.

18 Ström M. Bodeman G. Lindhagen J. Sjödahl R. Walan A. Cimetidine in parietal cell vagotomy in patients with juxtapyloric ulcer. Lancet 1984: ii: 894-7.

19 Boyd EJS, Penston JG, Johnston DA, Wormsley KG. Does maintenance therapy keep duodenal ulcers healed? Lancet 1988; i: 1324-7.

20 Boyd EJS, Wilson JA. Wormsley KG. Recurrent ulcer discase. In: Misicwicz JJ, Wood JR, eds. Ranitidine therapeutic advances. Amsterdam: Excerpta: Medica 1984.

21 Bardhan KD. Intermittent treatment of duodenal uleer with cimetidine. Br Med J 1980; 281: 20-2.

22 Bardhan KD, Bianchi Porro G. Bose K. et al. A comparison of two different doses of omeprazole versus ranitidine in the treatment of duodenal ulcers. $J$ Clin Gastroenterol 1986; 8: 408-13.

23 Miller JP, Farragher EB. Relapse of duodenal ulcer: does it matter which drug is used in initial treatment? Br Med J 1986; 293; 1117-8.

24 Bardhan KD. Singh S. Morris $P$, et al. Intermittent treatment for chronic duodenal ulcer: colloidal bismuth subcitrate versus ranitidine [Abstract]. (jut 1989; 30: A724.

25 Bardhan KD. Refractory duodenal ulcer. Gut 1984: 25; 711-7.

26 Hansen JH, Knigge U. Failure of proximal gastric vagotomy for duodenal ulcers resistant to cimetidine. Lancet 1984; ii: 84-5.

27 Bransom CJ, Boxer ME, Palmer KR. et al. Mucosal cell proliferation in duodenal ulcer and duodenitis. (jut 1981: 22: 277-82.

28 Bardhan KD. Hinchliffe RFC. Bose K, et al. Low dose maintenance treatment with cimetidine in duodenal ulcer: intermediate-term results. Postgrad Med J 1986; 62: $347-51$.

29 Brunner G, Creutzfeldt W, Harke U, Lamberts R. Therapy with omeprazole in patients with peptic ulcerations resistant to extended high-dose ranitidine treatment. Digestion 1988; 39: 80-90).

30) Bardhan KD. Refractory duodenal ulcer: a review. In: Bianchi Porro G. Bardhan KD, eds. Topics in peptic ulcer disease. Verona: Cortina International. 1987; 69114.

31 Bardhan KD, Cust G, Hinchliffe RFC, Williamson FM. Lyon $\mathrm{C}$. Bose $\mathrm{K}$. Changing pattern of admissions and operations for duodenal ulcer. BrJ Surg 1989: 76: 230-6. 